\title{
Plasma Kallikrein Deficiency
}

National Cancer Institute

\section{Source}

National Cancer Institute. Plasma Kallikrein Deficiency. NCI Thesaurus. Code C131648.

A coagulation disorder characterized by the partial or complete absence of plasma-type kallikrein activity in the blood. 